\title{
Problem-solving set as a function of number of reinforcements'
}

WILBERT S. RAY

COGNITIVE OPERATIONS LABORATORY, BETHANY COLLEGE

\begin{abstract}
College student Ss were given different amounts of training in solving water-jars problems by a long method; $1,2,4,6$, or 8 problems. The amount of set produced was measured by 30 two-method test problems, and the number of Ss completely set over the 30 prob*. lems increased in a positive growth function with number of training problems.
\end{abstract}

\section{Introduction}

Set in solving Einstellung or water-jars problems (Luchins, 1942) is defined in terms of the number of long-method solutions produced when $\mathrm{S}$ is given problems which may be solved either by the longer or by a shorter method. It has been reported (Gardner \& Runquist, 1958; Guetzkow, 1091; van de Geer, 1957) that an increasing number of training problems (reinforcements) increases the number of set solutions in succeeding two-solution problems, but this has never been shown in a simple fashion in which the number of training problems is varied and is followed by a reasonably large number of test problems. The present experiment does that. Numbers of training problems were $1,2,4,6$, or 8 , with 30 test problems used in each condition.

\section{Method}

Problems were presented in booklets made up of slips of paper with one problem on each. Ss wrote their solutions on the slips. All Ss were students in a course in General Psychology and were tested in one large group.

The first training problem was used as a sample, with the method of recording solutions illustrated on a chalkboard, and is therefore the same first problem for all groups. Four sequences of training problems and four of test problems were prepared, and the test problem sequences were rotated across the training problem sequences. The "sequences" in the groups with small numbers of training problems differed in the identity of the problems.

\section{Results}

The figures in Table 1 represent the number of Ss who were completely set in that they never used the short method in any test problem. Nine records were included as "completely set" although they contained from one to three anomalous (but not short-method) solutions, and in each case continued with long-method solutions. All of these records had at least 14 longmethod solutions after the last anomalous solution except in one case where there were only two. Additionally, two records were unusable because of defects in the
Table 1. No. of Ss showing set effect throughout testing

\begin{tabular}{llcc}
$\begin{array}{l}\text { No. of } \\
\text { reinforcements }\end{array}$ & $\begin{array}{l}\text { No. of Ss } \\
\text { using luing } \\
\text { method } \\
\text { throughout }\end{array}$ & $\begin{array}{l}\text { Total no. } \\
\text { of Ss }\end{array}$ & $\begin{array}{l}\text { Proportions } \\
\text { of Ss using } \\
\text { long method } \\
\text { throughout }\end{array}$ \\
\hline 1 & 12 & 28 & 0.43 \\
2 & 14 & 27 & 0.52 \\
4 & 15 & 27 & 0.56 \\
6 & 18 & 27 & 0.67 \\
8 & 15 & 21 & 0.71 \\
\hline
\end{tabular}

assembly of the test booklets, and four (all in Group 8) because of various idiosyncratic operations with training problems.

Remembering that "number of problems"' is rendered somewhat equivocal by the first problem's being used as an example, Table 1 shows that an increasing number of reinforcements of the long method solution produced an increasing amount of set. The best-fit line ${ }^{2}$ for the proportions of set Ss is a straight line with the equation $\mathrm{a}=0.41+0.04 \mathrm{n}$, which gives a root mean square deviation of $2.1\left(10^{-2}\right)$.

A chi-square analysis shows no significant differences among the frequencies, but the probability that each of four numbers will be higher than the preceding number is $1 / 16$, about a $6 \%$ confidence level.

\section{Diseussion}

These results agree with traditional learning results on the effects of increasing numbers of reinforcements in that the effect is a monotonic increasing function. A further increase in number of reinforcements would presumably produce a negative acceleration since there is an obvious asymptote at $100 \%$ of Ss completely set. It is improbable that increasing the number of test problems would change the results since such a large number of Ss were completely set over 30 problems.

There can be little doubt that this much of problemsolving behavior is to be categorized as learning behavior.

\section{References}

Gardner, R. A., \& Rundquist, W. N. Acquisition and extinction of problem-solving set. J. exp. Psychol., 1958, 55, 274-277.

Guetzkow, H. An analysis of the operation of set in problem-solving behavior. J. gen. Psychol., 1951, 45, 219-244.

Luchins, A. S. Mechanization in problem solving. Psychol. Monogr., 1942, 54, Whole No. 248.

Van de Geer, J. P. A psychological study of problem solving. Haarlem: Uitgeverij de Toorts, 1957.

\section{Notes}

1. This work was done under grant MH 08823-01 from the Public Health Service.

2. Thanks are due Richard Sha and James McKearney for producing this equation. 